\title{
Multilayered approach to patient safety culture
}

\author{
Teemu Reiman, Elina Pietikäinen, Pia Oedewald
}

VTT, Espoo, Finland

Correspondence to Dr Teemu Reiman, VTT, PO Box 1000, FIN-02044 VTT, Finland: teemu.reiman@vtt.fi

Accepted 11 November 2009 Published Online First 19 August 2010

\begin{abstract}
Background The concept of patient safety culture (PSC) has increasingly been used in the development of patient safety. However, no theoretical framework on the nature of the underlying phenomenon has been created. Multiple characterisations of the key dimensions of PSC exist, but they yield little theory on patient safety culture or its relation to patient safety. The authors propose a dynamic and multilayered construct of patient safety culture and illustrate the critical dimensions at each layer.

Conclusions PSC can be defined as the willingness and ability of an organisation to understand safety as well as the willingness and ability to act on safety. Patient safety requires controlling and steering the organisation, and being mindful of the social processes and psychological phenomena.
\end{abstract}

\section{INTRODUCTION}

Patient safety culture (PSC) has been proposed as a concept tackling the organisational properties of patient safety. The properties include the personnel's safety attitudes, beliefs and knowledge. The concept highlights the significance of group- and organisational-level processes for safety.

As recent safety research has pointed out, it is important to consider safety as something more than merely the absence of incidents. ${ }^{1-4}$ Furthermore, organisations should be treated not as mechanical machines but as dynamic sociotechnical systems. $^{4-7}$

Previous studies have demonstrated multiple characterisations of key dimensions of PSC. However, they yield little theory on PSC or its relation to patient safety. The underlying theoretical framework has remained implicit in most previous studies. $^{8-10}$ The advances made in organisational theory and safety science have not reached the concept of PSC. ${ }^{11}$ No coherent view of the contents of PSC has emerged.

This article proposes a new, dynamic and multilayered construct of PSC. We argue for a three-layer model of PSC that identifies the organisational dimensions, the psychological dimensions and the social processes. The layers are based on an analysis and synthesis of existing theories and case studies. The layers form the organisational potential for patient safety. We discuss the application and validity of the construct in light of cultural theories and existing knowledge of safety in complex systems.

\section{LAYERS OF PATIENT SAFETY CULTURE Organisational dimensions}

Most studies concerning PSC have approached the subject from the organisational science paradigm. Survey studies have revealed different sets of dimensions of PSC. Most of these dimensions can be called 'organisational' because they depict key activities of the organisation in ensuring patient safety (box 1). For example, when studying the psychometric properties of the Hospital Survey on Patient Safety Culture questionnaire, Sorra and Nieva arrived at a 12-dimension solution, separating the dimensions based on whether they measured unit- or hospital-level phenomena. Sexton et al considered only six dimensions central to patient safety, ${ }^{9}$ and Singer et al utilised the fivedimensional PSCI Culture Survey. ${ }^{10}$ Zohar et al studied the safety climate of nurses from the point of view of three caring dimensions at unit and hospital level. ${ }^{11}$

The accuracy of the reported dimensions is hard to evaluate because the theoretical reasoning behind them is either thin or altogether lacking. ${ }^{8-10}$ This reflects the theoretically underspecified nature of the construct of safety culture. ${ }^{4}{ }^{12-14}$ Moreover, researchers have sometimes combined a set of qualitatively different dimensions. For example, in the Safety Attitudes Questionnaire ${ }^{9}$ the dimensions of job satisfaction and stress recognition represent individual-level phenomena, whereas the dimensions of teamwork climate or safety climate represent organisational- or team-level phenomena. We argue that it would be useful to make these qualitative distinctions explicit. The organisational dimensions are only one, although highly important, layer of PSC.

Some of the variation in the organisational dimensions is explained by the fact that researchers have named the dimensions differently, even when the content is almost the same. In fact, if we look under the surface level of the dimensions, we find a rather coherent picture of the organisational dimensions important to safety. Certain common themes repeatedly come up in safety culture research, both in healthcare and in other domains. We summarise these in table 1.

'Organisational management system' refers to the documented work roles and safety responsibilities. Standardisation and use of formal procedures have increased in healthcare through the rise of the patient safety movement and evidence-based practice. ${ }^{15}$ The utilisation of instructions as guidelines and resources for action is important. At the same time, it should be understood that rules can only serve as support tools for decision-making. ${ }^{16}$

Management commitment to safety has been considered the most central component of safety culture since the formulation of the concept in the 1980s. ${ }^{17}$ Flin concludes that management commitment to safety has proven to be the most important organisational dimension also in healthcare. ${ }^{18}$ 'Actions of the management to promote safety' refer to the actions through which the safety 
Box 1 Dimensions of patient safety culture in empirical studies

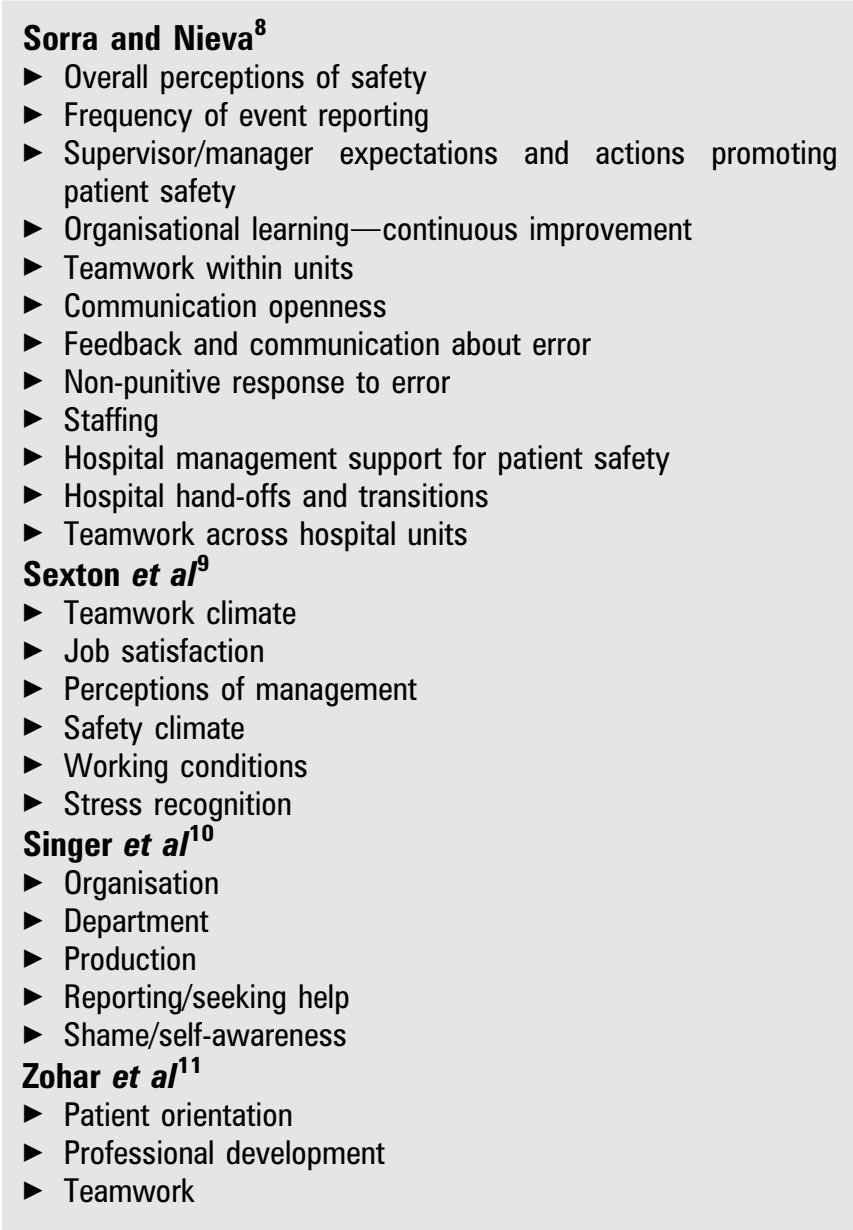

commitment of the management becomes visible. Examples are the prioritising of patient safety in the distribution of resources and a long-term plan concerning the development of patient safety. 'Actions of the immediate superior' refer to the way the supervisor shows her commitment to patient safety through her actions.

'Practices of cooperation' refer to the way personnel and teams work together in order to ensure patient safety and whether all the necessary information to perform the actual work is easily available. The importance of teamwork and communication to patient safety has been recognised in many studies. ${ }^{8-11} 19$

Table 1 Organisational dimensions of patient safety culture

Organisational management system
Actions of the management to promote safety
Actions of the immediate superior
Practices of cooperation
Communication and information flow
Practices of organisational learning
Management of competencies and training
Management of resources
Management of change
Management to third parties/subcontractors
Collaboration and information flow between units
Collaboration and information flow between professional groups

'Practices of organisational learning' include both the collective practices of continuous improvement ${ }^{8}$ and the ways in which errors are reported and utilised as opportunities for learning. 'Management of competencies and training' concerns the ways in which the organisation ensures that the personnel have the abilities necessary to do their work. It includes providing the necessary formal training and ensuring adequate supervision of interns and new employees. 'Management of resources' refers to the adequacy of working conditions and personnel resources. ${ }^{8}$

'Management of change' has recently received attention in the industrial safety domain. ${ }^{20}$ In healthcare, change management is not yet well established. However, large-scale technological changes and the economic pressure to rationalise healthcare are forcing organisations to pay more attention to how they handle changes. 'Management of third parties/ subcontractors ${ }^{21}$ rarely comes up in studies of PSC, but its importance to safety is growing through the increasing outsourcing of healthcare-related services.

'Collaboration and information flow between units' and 'collaboration and information flow between professional groups' are critical dimensions of PSC because healthcare organisations are typically large and complex, and the culture is often hierarchical and comprises strong professional subcultures. ${ }^{11} 2223$

\section{Social processes}

Social processes affect how things are interpreted, how practices are shaped and how meaning is created within the organisation. ${ }^{6} 2425$ Social processes deal with intentional changes, unintentional variations, trade-offs and reinterpretations of daily work. Time is an important component of these processes. Social processes can be seen as social mechanisms that 'quietly' shape organisational and psychological dimensions in the organisation. Table 2 depicts the most important social processes in terms of patient safety.

Collective sensemaking of events and incidents ${ }^{6} 25$ and the formation and maintenance of social identity ${ }^{26}$ are closely linked processes. Social identity refers to a sense of belonging to a certain organisation, profession or group, and the differentiations made between the in-group and other groups. The manner in which characteristics of organisational life affect behaviour depend strongly on the self-categorical meaning of those characteristics for the members of the organisation. ${ }^{26}$ For example, organisation members evaluate information in light of its source. The same information can be received very differently, even disregarded, if the messenger is from some other professional group (eg, a nurse) as opposed to a colleague (eg, a fellow doctor). Collective sensemaking is an ongoing social process of enacting organisational reality and generating the cues that are later used for interpretation. ${ }^{6} 25$ Thus, sensemaking is about creating a plausible narrative of ambiguous and uncertain events. This narrative creates expectations that guide attention in future. For example, during the flu season, a patient's symptoms of a sore throat or a headache are more easily interpreted as manifesting flu, since the diagnosis fits the context created by all the other patients.

Table 2 Social processes of patient safety culture

Collective sensemaking

Social identity maintenance

Optimising and local adaptation

Normalisation of cues

Embedding of conceptions 
Optimisation and adaptation of the work practices dictated by local demands ${ }^{27}$ have an impact on patient safety. Normalisation of cues can be seen as a process where repetitive cues such as oversensitive alarms, continuous overflow of patients or erroneous measurements become normalised and regarded as not requiring attention. ${ }^{28}$ This has negative consequences if the cue is important to patient safety. It is practical to ignore an oversensitive (and typically false) alarm, except for the one time that it signals a real threat.

Often, tools and technology mean whatever they have been used for in the past. ${ }^{29} 30$ The process of embedding conceptions and meanings within the technology, tools and procedures in organisations affects how the hazards and the demands of the work are understood. ${ }^{7}$ For example, the categories-reason for admission, previous known medical conditions - that exist in electronic patient records direct attention to those issues. In a similar manner, the design of an incident reporting system and its error categories already embeds a conception of what information is critical for improving patient safety.

Specification of social processes is challenging. It relies on indepth qualitative assessment and self-reflection by the organisation. Nevertheless, current theories in safety science have provided compelling evidence on the role of these processes in various organisational failures. ${ }^{27} 283031$ Thus, it is important to understand social processes in order to improve patient safety.

\section{Psychological dimensions}

The psychological dimensions of PSC indicate the subjective experiences and views of the personnel concerning their work. We have summarised the psychological dimensions of PSC in table 3. These dimensions have been identified in work psychological research in various domains. ${ }^{7} 3233$

When assessing PSC in an organisation, it is important to take notice of how the personnel experience their work (sense of control, responsibility and meaningfulness). It is also important to consider how the personnel view safety. For example, are errors considered individual faults or organisational-level problems?

It should not be taken for granted that the personnel understand the variety of safety hazards. ${ }^{34-38}$ In healthcare, the nature of hazards is complicated by the fact that patients suffer from various illnesses or injuries, some of which are fatal and some of which can become fatal if not diagnosed correctly and treated accordingly. Inadequate organisational practices and processes can pose additional hazards. Treatments also cause side-effects and are themselves sometimes hazardous. Finally, patients can create hazards either for themselves or for others, intentionally or unintentionally.

The psychological dimensions should create a mindset that is alert to the possibility of unpleasant surprises or unexpected events. This mindfulness refers to a state of mind where the healthcare professional is constantly trying to anticipate potential failure scenarios and update their knowledge of the unfolding situation. ${ }^{39}$

Table 3 Psychological dimensions of patient safety culture

Perceived meaningfulness of one's own work
Sense of control over one's own work and its results
Knowledge of organisational and interest groups' expectations concerning one's
own work
Sense of personal responsibility over one's own work and its results
Knowledge of the hazards and hazard mechanisms that can turn potential hazards into
actual harm
Knowledge of safety and the necessary means to achieve it
Knowledge of the organisational core task and its constraints and requirements

\section{RELATIONSHIP BETWEEN PSC AND PATIENT SAFETY}

Patient safety culture can be defined as the willingness and ability of an organisation to understand safety (and the hazards) as well as the willingness and ability to act on safety. PSC is a dynamic state produced by the three layers (figure 1). Even though the layers of PSC are inter-related, an understanding of each one is needed in order to evaluate and develop patient safety. Examples of positive behavioural manifestations of the layers are given in box 2 . The examples are based on our case studies and other literature. ${ }^{16} 26-283031$ The examples demonstrate how the safety effects of organisational and social dimensions are dependent on their effect on the psychological dimensions.

The psychological dimensions provide the individual preconditions for safe situational activity. The aim of safety management is to develop and sustain optimal psychological dimensions. The organisational dimensions are the layer where development activities are carried out and which can be managed by interventions and technological innovations. Social processes can explain why certain dimensions have formed in the way they have. PSC, when understood as a construct involving the three layers described above, can be seen as an indicator that comes close to measuring patient safety itself. PSC could provide a proactive indicator of patient safety.

Figure 1 illustrates that the organisational dimensions create the preconditions for the psychological dimensions and provide cues (actions, information, practices) for the social processes. Social processes in turn attribute meaning to the organisational dimensions and constrain or enable the development of psychological dimensions. Finally, psychological dimensions direct and steer the organisational dimensions. The content of the psychological dimensions feeds back into social processes and requires collective interpretation. Together these three layers form the organisational potential for providing safe care.

\section{CONCLUSIONS}

The paper proposed a theoretical framework and a measurement model for the concept of patient safety culture. This framework should be tested and verified empirically in future research. The framework viewed PSC as a multilayered construct. This view is different from many PSC studies that do not explicitly depict the qualitatively different layers behind the measurements and in fact, do not put PSC into a theoretical framework at all. According to the framework proposed in this article, patient safety requires controlling and steering the organisational dimensions, and being mindful of the social processes and the psychological dimensions.

PSC does not include the situational performance of individual workers. PSC is more about potential than actual performance. In real situations, the preconditions (potential) created by PSC actualise in a manner that is dependent on many task- and situation-specific variables. These include the nature of

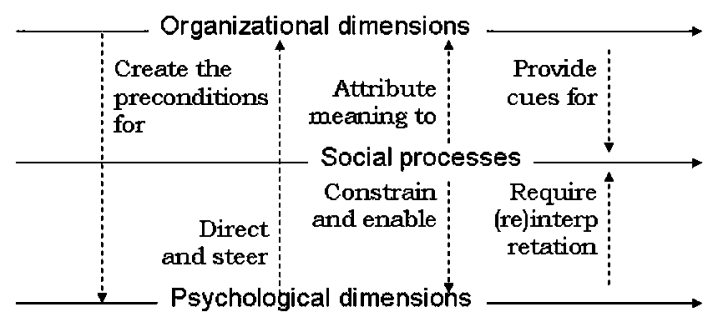

Figure 1 Layers of patient safety culture, showing their interrelatedness and how they affect each other. 
Box 2 Examples of concrete positive manifestations of the layers of patient safety culture

Examples of organisational dimensions

Management of third parties/subcontractors

Subcontractors are carefully introduced to the practices and safety issues of the organisation giving them a better understanding of how patient safety is assured.

\section{Management of change}

Risk analysis is conducted before technical or organisational changes leading to increased understanding of the hazards associated with change.

\section{Actions of the immediate superior}

Supervisor provides feedback on safety conscious behaviour, promoting employees' understanding of hazards, and expectations concerning patient safety.

\section{Examples of social processes}

Collective sensemaking

Reporting of errors and near-misses becomes an important part of daily work promoting increasing understanding of issues threatening patient safety.

\section{Social identity maintenance}

Social identity promotes high ethical standards (sense of personal responsibility) and acknowledgement of uncertainties in professional knowledge (understanding of hazards).

\section{Optimising and local adaptation}

Units are able to adapt to changing circumstances, such as a sudden increase in the flow of patients, without losing the big picture and all the while increasing their understanding of the means to achieve safe care.

\section{Examples of psychological dimensions}

Sense of control over one's own work and its results Realistic sense of control enables one to perceive one's capabilities and limitations, and to learn from one's job and learn about one's competence.

\section{Knowledge of organisational and interest groups' expec-} tations concerning one's own work

Good knowledge of expectations helps the personnel to concentrate their work on those issues that are considered important in the organisation and to know whether they are acting in line with common practice.

\section{Knowledge of safety and the necessary means to achieve} it

Understanding of the systemic nature of safety promotes cooperation and sharing of knowledge as well as the realisation that safety needs to be maintained and recreated in the daily work.

the illness or harm to the patient, and both the personal (work orientation, personality) and situational characteristics (fatigue, stress tolerance) of the clinician. However, PSC affects the possibilities for organisational learning from these specific situations. PSC affects patient safety in an individual case by creating the preconditions of work and influencing the situational possibilities for action. In the long run, PSC is postulated to give an estimate of the general level of patient safety.

The three layers of PSC can be studied by different research methods, both qualitative and quantitative. No one method is likely to encompass all layers of the culture. Thus, it is important to acknowledge which layer the methods measure and which layers are excluded. PSC research would benefit from a more explicit theoretical focus including explicating the premises concerning the concepts of organisation and patient safety.

Acknowledgements The authors acknowledge their fruitful discussions with four Finnish hospital districts on the application of the PSC construct. An earlier version of this paper was presented at the HEPS conference in Strasbourg, France, in June 2008.

Funding The Finnish Work Environment Fund, Eerikinkatu 2, Fl-00100 Helsinki, Finland. Competing interests None.

Provenance and peer review Not commissioned; externally peer reviewed.

\section{REFERENCES}

1. Dekker SWA. Ten Questions About Human Error. A New View of Human Factors and System Safety. Mahwah, NJ: Lawrence Erlbaum, 2005.

2. Hollnagel E. Barriers and Accident Prevention. Aldershot: Ashgate, 2004.

3. Rochlin GI. The social construction of safety. In: Misumi J, Wilpert B, Miller R, eds. Nuclear Safety: A Human Factors Perspective. London: Taylor \& Francis, 1999:5-23.

4. Reiman T, Oedewald P. Assessment of complex sociotechnical systems - theoretical issues concerning the use of organizational culture and organizational core task concepts. Saf Sci 2007;45:745-68.

5. Schultz M. On Studying Organizational Cultures. Diagnosis and Understanding Berlin: Walter de Gruyter, 1995.

6. Weick KE. Sensemaking in Organizations. Thousand Oaks, CA: Sage, 1995.

7. Reiman T. Assessing Organizational Culture in Complex Sociotechical Systems. Methodological Evidence from Studies in Nuclear Power Plant Maintenance Organizations. Espoo: VTT, 2007.

8. Sorra JS, Nieva VF. Hospital Survey on Patient Safety Culture. Rockville, MD: Agency for healthcare research and quality, 2004.

9. Sexton JB, Helmreich RL, Neilands TB. The safety attitudes questionnaire: psychometric properties, benchmarking data, and emerging research. BMC Health Serv Res 2006;6:44. http://www.biomedcentral.com/1472-6963/6/44 (accessed 15 Jul 2008).

10. Singer SJ, Gaba DM, Geppert JJ, et al. The culture of safety: results of an organization-wide survey in 15 California hospitals. Qual Saf Health Care 2003;12:112-18.

11. Zohar D, Livne Y, Tenne-Gazit 0, et al. Healthcare climate: a framework for measuring and improving patient safety. Crit Care Med 2007;35:1312-17.

12. Guldenmund FW. The nature of safety culture: a review of theory and research. Saf Sci 2000;34:215-57.

13. Hale AR. Culture's confusions [editorial]. Saf Sci 2000;34:1-14

14. Pidgeon N. Safety culture: key theoretical issues. Work Stress 1998; 12:202-16.

15. Claridge T, Parker D, Cook G. Pathways to patient safety. The use of rules and guidelines in health care. In: Walshe K, Boaden R. eds. Patient safety. Research into practice. Berkshire: Open University Press, 2006:198-205.

16. Oedewald P, Reiman T. Special characteristics of safety critical organizations. work psychological perspective. VTT Publications 633. Espoo: VTT, 2007. http://www.vtt.fi/inf/pdf/publications/2007/P633.pdf.

17. INSAG. Safety Culture. Vienna: IAEA, 1991.

18. Flin R. Measuring safety culture in healthcare: a case for accurate diagnosis. Saf Sci 2007;:45:653-67.

19. Leonard M, Graham S, Bonacum D. The human factor: the critical importance of effective teamwork and communication in providing safe care. Qual Saf Health Care 2004;13:85-90.

20. Grote G. Diagnosis of safety culture: a replication and extension towards assessing 'safe' organizational change processes. Saf Sci 2008;46:450-60.

21. Rollenhagen C, Westerlund J. Development of a safety climate questionnaire for nuclear power plants. In: Proceedings of Joint 8th IEEE HFPP/13th HPRCT, 2007.

22. Morgan PI, Obgonna E. Subcultural dynamics in transformation: a multi-perspective study of healthcare professionals. Hum Relat 2008;61:39-65.

23. Westbrook MT, Braithwaite J, Travaglia JF, et al. Promoting safety. Longer-term responses of three health professional groups to a safety improvement programme. Int J Health Care Qual Assur 2007;20:555-71.

24. Brown R. Group Processes. 2nd edn. Blackwell: Oxford, 2000

25. Weick KE, Sutcliffe KM, Obstfeld D. Organizing and the process of sensemaking. Organ Sci 2005;16:409-21.

26. Haslam SA. Psychology in Organizations. The Social Identity Approach. 2nd edn. London: Sage, 2004

27. Snook SA. Friendly Fire. The Accidental Shootdown of US Black Hawks over Northern Iraq. Princeton, NJ: Princeton University Press, 2000.

28. Vaughan D. The Challenger Launch Decision. Chicago: University of Chicago Press, 1996.

29. Weick KE. Organizational redesign as improvisation. In: Huber GP, Glick WH, eds. Organizational Change and Redesign: Ideas and Insights for Improving Performance. Oxford: Oxford University Press, 1993:346-82.

30. Hutchins E. Cognition in the wild. Cambridge, MA: MIT press, 1995 
31. Wears R, Perry S, McFauls A. 'Free fall' - a case study of resilience, its degradation and recovery in an emergency department. In: Proceedings of the Second Symposium on Resilience Engineering; 8-10 November 2006,

Juan-Les-Pins: France.

32. Hackman JR, Oldham GR. Work Redesign. Reading, MA: Addison-Wesley, 1980.

33. Clarke S, Cooper CL. Managing the Risk of Workplace Stress. London: Routledge, 2004.

34. Woods DD, Pattersson ES, Cook RI. Behind human error: taming complexity to improve patient safety. In: Carayon P, eds. Handbook of Human Factors and Ergonomics in Health Care and Patient Safety. London: Lawrence Erlbaum, 2007:459-76
35. Grote G. Understanding and assessing safety culture through the lens of organizational management of uncertainty. Saf Sci 2007;45:637-52.

36. Hopkins A. Lessons from Longford. The Esso Gas Plant Explosion. Sydney: $\mathrm{CCH}, 2000$.

37. Naevestad T-0. Safety understanding among crane operators and process operators on a Norwegian offshore platform. Saf Sci 2008:46:520-34.

38. Norros L. Acting under uncertainty. the core task analysis in ecological study of work Espoo: VTT, 2004

39. Weick KE, Sutcliffe KM. Managing the unexpected. resilient performance in an age of uncertainty. 2nd edn. San Francisco: Jossey-Bass, 2007. 